\title{
Ñuble, de Provincia a Región. La identidad geocultural como clave del desarrollo regional
}

\author{
Ñuble, from Province to Region. Geocultural identity as \\ a key to regional development
}

Armando Cartes Montory*

\section{RESUMEN}

La creación de la Región de Nuble, en 2017, fue la culminación de un largo proceso de reconocimiento de su identidad cultural y de recuperación de su jerarquía, en la división político- administrativa del país. Los estudios asociados a la nueva Región permitieron desnudar múltiples carencias. Estas se atribuyen a un frustrado desarrollo industrial, la crisis agrícola y el centralismo nacional e intrarregional. El presente artículo analiza la evolución histórica de la provincia de Nuble y sus proyecciones; su relación sistémica con Concepción y el proceso que la llevó a convertirse en la XVI Región de Nuble. Su restablecida regionalidad se estima como una oportunidad para enfrentar el rezago histórico y avanzar, en el plano económico y social, hacia una nueva etapa. El artículo establece que, aunque es demasiado pronto para obtener resultados concluyentes, su estrategia de desarrollo debe basarse en su potencial agroindustrial y en la fuerte identidad cultural que la caracteriza.

\section{SUMMARY}

Nuble Region's creation in 2017 was the culmination of a long process of recognition of its cultural identity and recovery of its hierarchy in the country's political-administrative division. Studies associated with the new region revealed many shortcomings, attributed to frustrated industrial developments, agricultural crisis, and national and intraregional centralism. This article
Palabras clave: Región de Nuble, regionalización, identidad regional, vocación agrícola.
Keywords:
Ñuble region,
regionalization,
regional identity,
agricultural
vocation.

\footnotetext{
* Chileno. Doctor en Historia, Profesor titular e investigador del Programa CreaSur, Universidad de Concepción, Chile. Director del Archivo Histórico de Concepción. E-mail: acartes@udec.cl
} 
analyzes the historical evolution of the province of Nuble and its projections; its systemic relationship with Concepción and its process led it to become the 16th Region of Nuble. Its re-established regionality is considered an opportunity to face the historical lag and advance, in the economic and social field, towards a new stage. The article states that, although it is too early to obtain conclusive results, its development strategy must be based on its agro industrial potential and the strong cultural identity that characterizes it. 
La Región de Ñuble es la más joven de las 16 regiones en que actualmente se divide administrativamente el país. Establecida en 2017, por la ley 21.033, su existencia como Región comienza el 6 de septiembre de 2018. Sus raíces se hunden, no obstante, en forma muy profunda en la historia patria, ya que formaba parte del "Chile histórico" de los tiempos coloniales, que se extendía desde el despoblado de Atacama hasta la línea de Frontera, situada al sur del Biobío. Ñuble se situaba en la histórica provincia de Concepción, a la que abastecía y con la cual formaba una línea de defensa, "el antemural de los infieles", que protegía al Chile central, en los años más duros de la Guerra de Arauco.

Durante los siglos coloniales fue un importante mercado y centro de producción agrícola que articulaba el Chile central con la Frontera, y se vinculaba al mercado peruano por el puerto de Tomé y al oeste argentino a través de la cordillera. Su fuerte impronta agrícola y cultural gestó una identidad territorial que cataliza en 1848 con la creación de la provincia de Ñuble. Con diversas transformaciones, subsiste hasta 1974, cuando se establece la actual división administrativa del país. Aunque no pierde entonces su nominal condición de provincia, queda subordinada a la Región del Bío-Bío y a su capital, la ciudad de Concepción.

La provincia exhibía un rezago que puede asociarse a diversos procesos, tales como la política de desarrollo industrial forzado, aplicada desde 1940, que castigó a las regiones agrícolas, el minifundio y, en décadas recientes, la introducción de cultivos forestales, con poco impacto en la economía local. Lo anterior dio lugar a la migración de la población rural a las ciudades y explica los elevados niveles de pobreza multidimensional de la región, en comparación con los promedios nacionales.

La responsabilidad por el retraso relativo se atribuía también a variables político- administrativas. Al centralismo endémico del país, en efecto, que gravaba el desarrollo de las provincias periféricas, se añadía el centralismo intrarregional, en opinión de las elites locales, generando una demanda de autonomía. Esta se expresó, desde fines del siglo pasado, mediante la pretensión de formar una nueva región, que devolviera la capitalidad a Chillán y permitiera — paradojas del centralismo- mantener un vínculo directo con Santiago. Fue la tarea que asumió un comité muy amplio de vecinos, al que se asociaron todos 
los municipios de la futura región. Tras veinte años de incesante actividad política, cultural y comunicacional, logró su objetivo, aunque solo cuando el proyecto fue asumido por dirigentes políticos regionales y sucesivos gobiernos nacionales.

En el presente trabajo pretendo analizar el decurso histórico de la provincia, en diversos planos. Es necesaria una mirada integral, que supere los estrechos marcos de las divisiones administrativas, para abordar las complejidades de los procesos -económicos, políticos, socioculturales- que han conformado la actual región. Aunque su evolución, en tiempos coloniales y republicanos, siempre ha estado asociada a la cercana Concepción y a la gran Región del Biobío, es necesario pensarla ahora de manera diferente. Está en elaboración una Estrategia Regional de Desarrollo propia y distinta de aquella que compartía con el Biobío. Metas, planes, objetivos y proyectos deben reflejar las prioridades y necesidades definidas desde y por la gente del Ñuble.

En la primera parte abordo la evolución del territorio y el poblamiento provincial desde tiempos prehispanos hasta las postrimerías coloniales. Se revisa la azarosa existencia de la capital, Chillán, marcada por exigencias militares y la fundación de diversas ciudades y villas que dieron origen a las actuales comunas. La función de articulación económica del mercado de Chillán cruza el tránsito republicano; este da lugar a un desarrollo industrial forzado y a una agricultura que no logra modernizarse. Así sorprende a Chillán y sus ciudades cercanas el gran terremoto de 1939, del cual emergerá una ciudad moderna y una ruralidad que busca su destino en el rubro agropecuario y la industria forestal. La absorción por la Región del Biobío, desde 1974, representa un interregno marcado por cierta languidez, que se espera superar con la recuperada regionalidad. Son las etapas del presente trabajo, que concluye con un moderado optimismo, mirando en prospectiva los años próximos de Ñuble.

En la preparación de este trabajo he consultado información geográfica e histórica obtenida de la amplia bibliografía que se acumula sobre Ñuble y sus comunas. También los estudios realizados con ocasión del proyecto de (re)crear la región, la tramitación legislativa y las múltiples gestiones de los promotores de la iniciativa. El objetivo ha sido, en la brevedad de un trabajo de esta clase, dar una mirada, a la vez actual y retrospectiva, a la antigua provincia y nueva Región de Ñuble. 


\section{La evolución de la provincia}

Durante los siglos coloniales, Nuble formó parte de la gran Provincia de Concepción y luego de la Intendencia homónima, que se extendía desde el río Maule a la Frontera. Fue así hasta la aprobación de una nueva división político-administrativa, por decreto de 31 de enero de 1826, en el marco de las leyes federales, que se considera la primera división política administrativa de Chile republicano. Si bien estas no perduraron, sí lo hizo la división provincial, aunque sus deslindes sufrieron modificaciones con el tiempo. De acuerdo con el decreto de 31 de agosto de 1826, la Quinta Provincia se extendía desde el río Maule hasta el río Ñuble "en su nacimiento de la Cordillera, siguiendo su curso hasta su confluencia con el Itata, y desde aquí de este río hasta su desembocadura en el mar. Esta provincia se denominará Maule; su capital, la villa de Cauquenes". A continuación, la Sexta Provincia iba inmediatamente al sur de esta, "hasta lo que hoi se reconoce con el gobierno de Valdivia. Esta provincia se denominará Concepción; su capital, la ciudad de este nombre" (Chile, 1889: 243). Anotemos que esta división no estuvo exenta de dificultades, pues la ciudad de Chillán solicitó, sin éxito, erigirse como capital de la provincia de Concepción en octubre de 1823, y luego, en noviembre de 1826, unirse a la provincia del Maule, con argumentos "de corte pragmático y estratégico, como la seguridad ante invasiones costeras y un mejor acceso a la capital" (Sanhueza, 2008: 479; Estefane, 2017: 87).

La Provincia de Ñuble, antecesora de la actual Región, fue creada por ley de 2 de febrero de 1848, mediante la fusión de dos antiguos departamentos, el Departamento de Chillán, perteneciente a la antigua Provincia de Concepción y el Departamento de San Carlos, que era parte de la Provincia del Maule. La creación de la provincia respondió a la necesidad de establecer un mayor control territorial, al igual que las demás que fueron creadas en las siguientes décadas, en la medida que el Estado instalaba su burocracia a lo largo del territorio. En el caso de Concepción en particular, de proverbial altivez, protagonista en la organización de la república y que se levantará en armas en 1851, el control era especialmente crítico. Fue acentuado tras su derrota con la creación, en 1852, de la provincia de Arauco, que completaba con Ñuble la reducción de su tradicional territorio (Sagredo, González y Compan, 2016). 
En 1884 se crearon los departamentos de Bulnes y Yungay, que antes formaban parte del departamento de Chillán. En 1927 se agregó el Departamento de Itata, segregado de la provincia de Maule. Se crea también la comuna de Quillón en el Departamento de Bulnes, que antes era una subdelegación del Departamento de Puchacay, Provincia de Concepción (Chile, 1927).

Durante estos años, como en otra parte hemos escrito,

"su ubicación estratégica como una zona articuladora de los intercambios con la frontera de guerra antaño y luego con la región fronteriza, la dotaron de gran centralidad. Mantuvo un intenso contacto con el oriente argentino, a través de una cordillera llena de boquetes, que sólo en décadas recientes se han cerrado y esperan pronto un nuevo ciclo de contactos y comercio. Hacia la costa, también sus vínculos fueron intensos: proveyendo y guardando las espaldas de Concepción, cuando esta urbe era cabeza de la ocupación militar; recibiendo a los viejos soldados que sentaban sus reales en las orillas de Itata; en el trigo y el vino que miles de carretas llevaban al puerto y los molinos de Tomé; $y$, en la década recientes, en el desarrollo turístico de la franja costera de Dichato a Curanipe" (Cartes, 2015: 14).

En julio de 1974, en virtud del Decreto ley $N^{\circ} 575$, se crearon las actuales regiones y, en 1975, el Decreto ley $\mathrm{N}^{\circ} 1.230$ dividió las regiones en 48 provincias. La antigua Provincia de Ñuble es suprimida y se crea en su lugar una nueva que pasa a integrarse a la Región del Biobío. Esta provincia, que subsistió cuarenta y tres años, tenía una superficie total de 13.178,5 kilómetros cuadrados y estaba conformada por veintiún comunas. Su capital fue la ciudad de Chillán.

Consignemos que la división de 1974 creó regiones y provincias para el gobierno y la administración interior, a cargo de intendentes y gobernadores respectivamente, y, para la administración local, dividió el territorio en comunas. El plan tenía antecedentes en diversos proyectos propiciados por la Corporación de Fomento de la Producción y la Oficina de Planificación Nacional en décadas previas, que, en general, favorecían la creación de territorios más amplios, en la lógica de polos de desarrollo, capaces de mayor autonomía (Comisión Nacional de la Reforma Administrativa, 1976). En 1964, entre las primeras me- 
didas de la administración de Eduardo Frei Montalva, se estableció la Región del Biobío como un plan piloto, más bien como una instancia de coordinación que reunía a los intendentes de las provincias de Biobío, Concepción, Malleco, Nuble y Arauco (Oficina de Informaciones y Difusión de la Presidencia de República, 1966).

\section{Un territorio cargado de historia}

Pasaremos revista, a continuación, a su evolución en tiempos coloniales en diversos planos. La riqueza de su pasado histórico se vincula a procesos centrales de la formación del país. Aunque muy ligada a lo rural, su fuerte identidad incluye dimensiones adicionales que justifican, en lo cultural, lo social y lo económico, su exitosa demanda por convertirse en región.

\section{Los habitantes prehispánicos}

El territorio de la actual Región estuvo habitado por diversas etnias, en distintos estadios culturales, desde hace más de siete mil años. Estos grupos - premapuche, picunches, chiquillanes y pehuenches-se distribuían en la precordillera, el llano y la planicie litoral. Así, se conoce una agrupación premapuche que tuvo su hábitat en las cercanías del río Ñuble, ribera abajo del sector de Nahueltoro, sector Muticura, donde existe hasta hoy un peñón con algunos petroglifos, huella visible de su presencia. Los primeros asentamientos humanos comprobados se hallan en el litoral de Cobquecura y en las cavernas de Quilmo, hito arqueológico situado al oriente de Chillán Viejo, por nombrar algunos hábitats primigenios.

El grupo más caracterizado en los primeros tiempos de la Conquista fueron los llamados "chiquillanes", pueblo nómade recolector que habitaba preferentemente en el sector cordillerano de la zona central, que se extiende desde Los Andes hasta las cercanías de Chillán. Su subsistencia se basaba en la caza de animales, como guanacos, ñandúes y pumas, entre otros. Solían repartirse en pequeñas comunidades de menos de cien individuos para recolectar alimentos. Se les consideraba aguerridos y "salvajes" en cuanto a sus costumbres. Una de las tantas teorías respecto del nombre de "Chillán" lo asocia a una variación de la voz "chiquillanes". Los españoles confundieron a estos con los pehuenches, por su cercanía en los territorios que habitaban, pero 
el nivel de desarrollo de estos últimos lo hacen un pueblo distinto (Cartes y Reyes, 2016: 35-36; Gómez, 1889: 300).

También durante el siglo XVI, en las proximidades del río Ñuble, hubo varios asentamientos mapuche picunche provenientes del norte del río Biobío. Eran de carácter pacífico y sus actividades cotidianas eran la pesca, la recolección, la caza y la agricultura. Ya desarrollaban una cierta artesanía utilitaria.

Los pueblos prehispánicos comprendían agrupaciones de diez o quince ranchos dependientes de un solo cacique, relacionados por sus principales actividades económicas, que consistían en agricultura, cerámica y elaboración de tejidos. En esta tierra se encontraban los rancheríos de Quinchamalí, Itihue, al oriente del actual San Carlos; Quillenhue, el actual Chillán; Roblería, cerca de Coihueco; Huechupín, cercano a Quinchamalí; Vegas de Itata, Buchupureo, Coelemu, Cato, Quinel, cercano al río Itata y la caleta de Cobquecura. Todos ellos constituyeron la base de futuras villas, pueblos o ciudades. La referencia nos indica la existencia de pueblos de pescadores y de agrupaciones en el llano, a lo que se sumaron, posteriormente, los pueblos de indios establecidos por los españoles. Allí se encuentran las raíces genéticas que, junto a la fusión con la sangre española, han dado vida a la población actual de la zona (Pedrero, 2017: 27; Medina, 1952: 163).

\section{El poblamiento hispano}

En 1536 una hueste de setenta hombres, comandada por Gómez de Alvarado, fue enviada por el adelantado Diego de Almagro con el fin de explorar el sur de Chile. En la confluencia de los ríos Itata y Ñuble la fuerza española se enfrenta por primera vez con el pueblo mapuche, en el combate de Reinogüelén. Según Diego de Rosales, el resultado de este combate fue de tres españoles heridos, doscientos indígenas muertos y la pérdida de dos caballos (Rosales, 1877). En Reinogüelén los castellanos percibieron por primera vez la fiereza de los naturales determinados a expulsar a los invasores.

Francisco de Aguirre fue el primer jefe español con milicias que atravesó el territorio hasta el Itata (Cartes y Arriagada, 2008). A orillas de este río y frente a las tierras del cacique Quinel, levantó un pequeño fuerte y se guareció en él, resuelto a esperar allí a Pedro de Valdivia. 
Transcurridos algunos años, en 1550, en plena Conquista, Pedro de Valdivia, capitán extremeño, gobernador de Chile, fundador de Santiago y Concepción, entre otras ciudades, reafirmando su autoridad sobre la región, concede la encomienda Toquihua, comprendida entre los ríos Maule y Nuble, al negro Juan Valiente, como compensación por su desempeño en sus huestes y en la batalla de Quilacura (1544). Fue la primera concesión de tierras bajo la figura de encomienda en Nuble. Cabe mencionar que Juan Valiente, un personaje semiolvidado por la historiografía, fue uno de los primeros negros llegados a Chile, compartiendo el propósito de conquista. Vino con Almagro en 1535 y retornó con Valdivia, junto al cual murió en la batalla de Tucapel, en 1553 (Restall, 2000). ${ }^{1}$

Valdivia concedió en encomienda al capitán Pedro León Fernández el territorio correspondiente al valle del río Chillán y sus indígenas, incluyendo a sus caciques, al oriente de la encomienda de Valiente. Por abandono de León, el conquistador la cedió a otro vecino de Concepción, el capitán Hernando de Huelva. ${ }^{2}$ Cercano a ese territorio, en 1551, el conquistador había otorgado encomienda sobre los caciques Tolmillán y Lobolián y sus tierras, correspondientes a la actual comuna de Bulnes, al soldado español Ortuño Jiménez de Vertendona, miembro de su hueste y vecino fundador de la ciudad de Concepción, regidor de ella y corregidor de Cañete. La parte occidental de la actual provincia fue asignada al conquistador Giraldo Gil. Concedió también Valdivia una encomienda a Antonio Beltrán, traspasando en 1552 a Antonio Lozano "dichos caciques entre los ríos de Itata y Maule, más cercanos a los de Itata", siendo Lozano uno de los vecinos fundadores de la ciudad de Concepción (Roa, 1945: 244). Estos conquistadores, dice Reinaldo Muñoz O., fueron los primeros hacendados o encomenderos que hubo en estas tierras, aportando los primeros gérmenes de la civilización europea, la cual echó las bases de la agricultura y de la industria chilena, fuentes poderosas de riqueza (Muñoz, 1921: 8).

Pasados algunos años, un alto número de picunche del centro de Chile, tras la rebelión de Michimalonco, comenzó a mejorar su trato

1 Sobre él existe, incluso, una novela gráfica (Carvajal, s/a) y una novela histórica (Gomáriz, 2016).

2 Huelva hace dejación de los indígenas encomendados en 1559, a su deudo Diego de Aranda (Roa, 1945: 242). 
con los españoles y, como indios auxiliares, los reforzaron en sus enfrentamientos con los mapuche. Muchos de ellos instalaron sus rucas en los alrededores de las ciudades recién fundadas, desarrollando relaciones sociales y comerciales con sus habitantes. Los valles del Itata y del Ñuble constituyeron un hábitat para estos pueblos, que ya habían evolucionado al nivel agroalfarero, lo que se manifestaba en sus actividades de labranza, pesca, recolección de frutos silvestres y artesanía utilitaria en greda (Pedrero, 2017: 28).

\section{Fundación de Chillán}

El poblamiento sistemático de Ñuble se gesta en la ribera norte del río Chillán, en la segunda mitad del siglo XVI. Habiendo sido fundadas algunas ciudades como Concepción y fuertes al sur del río Biobío, en pleno proceso de Conquista, el gobernador de Chile Rodrigo de Quiroga, miembro de la hueste que acompañó a Pedro de Valdivia, consideró construir un fuerte a orillas del río Chillán. La guerra de Arauco, que atrajo siempre hacia el sur la atención y el esfuerzo de civiles y militares, había pospuesto la fundación, pero las circunstancias urgían la creación de una ciudad entre el Maule y el Itata, que sirviera de base entre Santiago y Concepción.

La misión fue encomendada a su yerno, el mariscal Martín Ruiz de Gamboa, el 24 de agosto de 1579, día de San Bartolomé, de allí su nombre. La construcción provisoria de un fuerte era, a la vez, algo estratégico y humanitario, pues servía como sitio fronterizo para acoger a los colonos que pudieran huir de los levantamientos mapuche al sur del Biobío y para descanso de las tropas. El cronista Córdoba y Figueroa manifiesta: "deseando el gobernador (Quiroga) aliviar accidentes de altas consecuencias en lo futuro y poner el reino en estado de mayor seguridad, dispuso el fundar una ciudad".

Al poco tiempo, el 25 de febrero de 1580, fallece en Santiago el gobernador, sucediéndolo Ruiz de Gamboa, quien, en uno de sus viajes al sur, cumplió la misión de fundar una ciudad a poca distancia al oriente del fuerte, en la ribera norte del río Chillán. El nombre del río, que después se adopta para nombrar a la ciudad, ha provocado controversias. Algunos manifiestan que deriva del zorro chilla; otros, que corresponde a la contracción de la palabra "chiquillán", nativos nómades de la precordillera que recorrían en forma permanente esas tierras. Dice 
Fernando Martínez Labatut respecto de este topónimo: "río, montaña, valle e indígenas recibieron igual nombre, Chillán". Aún se sostiene, con buenos argumentos, que sería una voz mapuche que significa "Silla del Sol”, proveniente de chilla-antu, la visión del Sol en los amaneceres de verano (Martínez, 1980: 9).

Haciendo los aprestos pertinentes, el 26 de junio de 1580 el gobernador Martín Ruiz de Gamboa encabezó la ceremonia de fundación de San Bartolomé de Gamboa de Chillán, acompañado por las futuras autoridades locales, los primeros habitantes (vecinos), algunos de los cuales tenían residencia en Concepción, pero poseían tierras cerca de la nueva ciudad, y un grupo de indígenas yanaconas y amigos picunche, quienes aportaron la mano de obra para las construcciones. El sitio fue escogido por sus condiciones estratégicas, en una pequeña terraza, en un valle muy pródigo para la agricultura, con un terreno más alto al norte que sirviera de atalaya para otear el horizonte y prever un asalto indígena. La nueva ciudad estaba destinada a apoyar a los naturales amigos y defender a los colonos de los ataques de chiquillanes, pehuenches y mapuche, asegurando el normal tráfico de tropas y bagajes entre Santiago y Concepción. Importante era, además, proteger la producción agrícola para abastecer esta última ciudad, centro militar del Reino de Chile.

Así surge la ciudad con el nombre de San Bartolomé; en los documentos se llamó San Bartolomé de Gamboa, nombre que más tarde se cambió por San Bartolomé Gamboa de Chillán, luego San Bartolomé de Chillán, para finalmente ser denominada con el nombre de "Chillán”. En 1610, según un informe presentado por un oidor de la Real Audiencia de Santiago al rey, la ciudad tiene 52 casas, de las cuales ocho son de teja, 39 con techo de paja y cinco con buhío de ramas y paja, una iglesia parroquial, un convento de Santo Domingo con tres religiosos, otro de San Francisco con seis hermanos y otro de La Merced, con tres religiosos. En 1620 el padre Valdivia, promotor de la guerra defensiva, informaba que se explotaban 72 estancias ese año, asegurando que en la ciudad todas las casas eran de adobe y teja, en vez de las construcciones de paja.

En 1655, bajo la nefasta administración del gobernador Antonio de Acuña y Cabrera, se produjo una gran sublevación que costó a Chillán su destrucción. Entre el Maule y el Biobío los indígenas asaltaron, 
quemaron las casas de los fundos, mataron y cautivaron a cientos de habitantes, arrollando víveres y ganado. Fueron saqueadas 390 estancias, quitaron 400 mil cabezas de ganado y cautivaron mil trescientos españoles. El gobernador fue depuesto por el enfurecido pueblo de Concepción. A mediados de marzo no quedaban sino ruinas y el recuerdo de lo que había sido San Bartolomé de Gamboa de Chillán. Los habitantes permanecieron ocho años diseminados en una larga faja de tierra, parte al amparo del fuerte militar vecino al camino de Santiago, parte en caseríos improvisados a lo largo del río y en las casas de los fundos vecinos (Villalobos, 1995: 60-63).

\section{La "llave del Reyno"}

En 1662 asume como gobernador Ángel de Peredo, a quién se debe el fin del forzado destierro de los vecinos de Chillán. Asumido el mando, construye varios fuertes en la costa del Biobío y otros en la línea fronteriza, dictando acertadas medidas de buen gobierno, entre ellas la de reconstruir la ciudad.

Se retomaron las labores agrícolas en las estancias vecinas, sus dueños comenzaron a retornar a sus propiedades. Se les ayudó en la adquisición de herramientas, de semillas, de animales de labranza y de crianza, y se les auxilió en dinero para la reconstrucción de edificios urbanos y rurales. En diciembre de 1663 se habían construido treinta casas de material sólido, una capilla, dos conventos - los de Santo Domingo y San Francisco-, hornos de cocer pan y se contaba con agua del molino antiguo, como la implementación en la plaza del árbol de la justicia. Se levantó un fuerte con guarnición de 40 hombres, susceptible de alojar más de 200 soldados (Pedrero, 2008: 24).

El 1 de enero de 1664, en la sala del Cabildo, el gobernador Peredo encabezó la ceremonia de refundación. La llamó entonces "la llave del Reyno", por su rol articulador entre la frontera de guerra y el centro del país. Se nombraron las nuevas autoridades y se entregó el estandarte real para su custodia. Por orden del gobernador Juan Henríquez se crea en 1672 el pueblo de Huambalí, hoy extenso barrio de la ciudad, con las reducciones del cacique de ese nombre, traídas desde La Imperial, con toda su gente, conformando 280 familias, a las cuales se asignaron solares. 


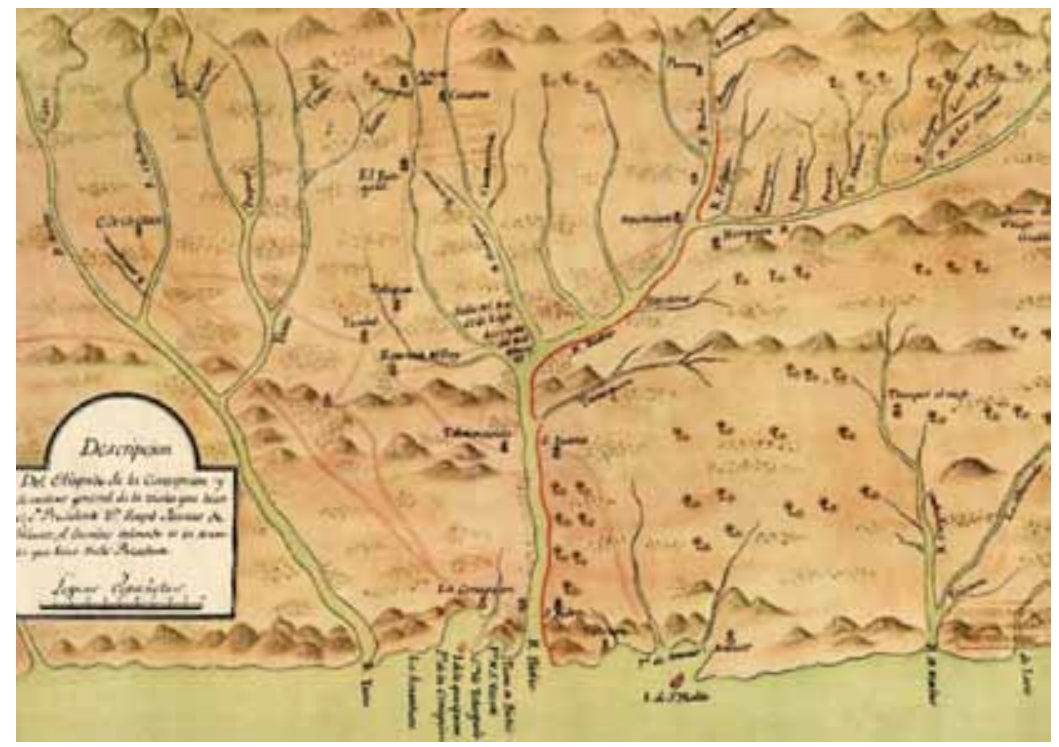

Figura $N^{\circ} 1$. Descripción del Obispado de Concepción y derrotero de la visita que hizo el Sr. Presidente Dn. José Manso de Velasco en 1743.

Fuente: Cartografía hispano colonial de Chile, II Atlas, Homenaje del Ejército de Chile a José T. Medina, Santiago, 1952.

El destino de la ciudad de Chillán ha estado asociado a grandes calamidades. El 25 de mayo de 1751, durante la noche, un violento terremoto azotó con mucha furia la región del Maule al sur. En Chillán, el vecino río Nuble, muy crecido por el invierno, se vació repentinamente sobre la ciudad por efecto de los temblores. Ante tal destrucción y el temor generalizado, se resolvió el traslado de las habitaciones a la loma del Alto de la Horca.

Se determinó construir la nueva ciudad en el lugar donde estaban muchos guarecidos; ya se habían construidos casas y habilitado una iglesia. El 25 de septiembre de 1751, el gobernador Ortiz de Rozas, cumplida la formalidad de la realización de un cabildo, firma el acta de autorización del traslado e instalación. La ciudad, por aquel entonces, contaba con mil habitantes y una guarnición de quinientos soldados y es lo que hoy corresponde a Chillán Viejo.

Ochenta años más tarde, la ciudad volvería a destruirse.

“Chillán, hacia el año 1835, tenía aproximadamente seis mil habitantes. Sus calles eran angostas y las casas, en su mayoría de ado- 
be, lucían las fachadas blanqueadas con cal, lo que le daba un tono uniforme a toda la ciudad; sobresaliendo los edificios de los conventos de San Francisco, La Merced y de Santo Domingo. Contaba con un hospital, dos escuelas de niños, una municipal y la otra de los padres franciscanos y también con cinco vigilantes encargados del orden público" (Leaman de la Hoz, 1982: 1).

El día 20 de febrero, a las once y cuarto de la mañana, los chillanejos sintieron un potente ruido subterráneo, que fue el preludio de un fuerte terremoto que afectaría a gran parte de la región central del país. Chillán fue completamente destruido por el sismo, "salvo parte del hospital, una sala de la cárcel y una que otra casa". Al ocurrir de día, precedido por un fuerte ruido, permitió a los vecinos ponerse a resguardo, muriendo solo ocho personas. La comisión que evaluó los daños estableció que cayeron 156 casas y nueve edificios públicos fueron destruidos (Reyes, 1999: 17-25). En las tradiciones del siglo XIX figura como "La Ruina” en Concepción y Chillán, término adoptado finalmente por los historiadores para mencionar este catastrófico suceso.

Al reunirse el Cabildo Abierto al día siguiente del sismo, citado por el gobernador, se observó desde el primer momento dos tendencias respecto a la reconstrucción de la ciudad: unos apoyaban hacerlo en el mismo lugar y otros propiciaban el traslado. La posterior visita del intendente José Antonio Alemparte fue decisiva, ya que adhirió al traslado, por variadas razones, entre ellas, permitir renovar el enclave con casas cómodas, mejor delineada, con un gusto uniforme y con calles anchas. Tras reuniones y acuerdos entre el cabildo, el intendente y el gobierno en Santiago, que intervino, con fecha 23 de octubre de 1835 se dicta un decreto presidencial "que declara de utilidad pública la traslación de la ciudad de Chillán". Era entonces presidente de la República José Joaquín Prieto, quién había sido gobernador de la provincia por algunos años.

La resistencia al cambio fue notoria, por lo que, hasta mediados de la década de 1840, en Chillán nuevo había menos población que en el pueblo antiguo. El crecimiento se fue acelerando, aumentó el comercio con foco en la feria, pero también con comercio establecido con algunas tiendas y pulperías. Se creó una escuela fiscal para hombres que, junto a la municipal y una escuela particular de niñas, fueron las 
primeras instituciones educacionales de enseñanza de esta década, presentando el aspecto de una verdadera ciudad. Esto último motivado por haberse construido varias casas, un hospital, la cárcel, la recova y los edificios públicos. El censo de 1854 ya señalaba una población de 12.665 habitantes, de los cuales ocho mil residían en el viejo pueblo (Reyes, 1999: 17-25).

\section{Fundaciones urbanas del siglo XVIII y XIX}

En la segunda mitad del siglo XVIII el panorama poblacional se desprende del informe redactado por el fraile y doctor Joseph de la Sala, secretario del obispo de Concepción Pedro Ángel de Espiñeira, tras la visita de ambos por su jurisdicción entre 1765 y 1766 (Sala, 1986). Se registraba la realidad de los curatos y doctrinas de Ninhue, Perquilauquén, Chillán y Quirihue. Respecto de Chillán, señala la existencia de 272 casas de diverso tipo de techo, teniendo la parroquia una viceparroquia en Pemuco y una capilla a orillas del estero Gallipavo. Evidencia la existencia de tres pueblos de indios: Quinchamalí, con un cacique y doce indígenas; Guambalí, cuatro caciques y 34 indígenas; y Roblería, cerca del actual Coihueco, con un cacique y 14 indígenas. La doctrina de Chillán alcanza a 5.748 adultos, entre españoles e indígenas.

El curato de Quirihue estaba conformado por dos capillas viceparroquias, una en el sector Quilpolemo y otra cercana a la costa, atendiendo una población adulta de 2.018 individuos. En Ninhue el número de adultos era de 2.717 individuos. El curato de Perquilauquén contaba con dos capillas, una a orillas del río homónimo y la otra a orillas del río Ñuble, con una población de 2.631 españoles y 352 indígenas a cargo del cacique de Cocharcas.

El gobernador de Chile, Domingo Ortiz de Rozas, responsable de la expansión del poblamiento en estas tierras, funda la ciudad de San Antonio Abad de Quirihue el año 1749 y, al año siguiente, la Villa de Jesús de Coelemu. Estas dos villas fueron incorporadas estratégicamente a la ruta caminera con las ciudades de Concepción y Cauquenes, dando forma al Camino Real. En 1751 fue fundada la villa La Candelaria, y en 1754 la villa Natividad, ambas cerca del río Perquilauquén, en la latitud del actual San Gregorio y al noreste de la actual ciudad de San Carlos, pero tuvieron corta existencia. 


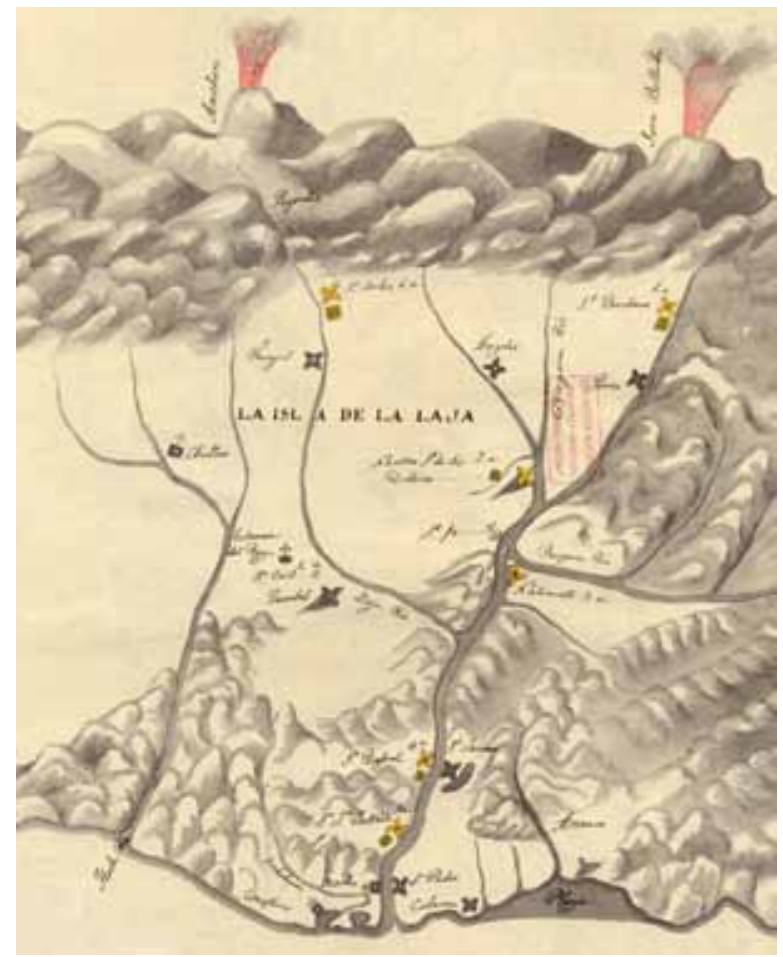

Figura $N^{\circ} 2$. Croquis de la Isla de la Laja, 1757.

Fuente: Cartografía hispano colonial de Chile, II Atlas, Homenaje del Ejército de Chile a José T. Medina, Santiago, 1952.

A comienzos del siglo XIX prosigue la expansión urbana. Por iniciativa del gobernador mariscal Joaquín del Pino, el 3 de julio de 1800 es fundada la ciudad de San Carlos de Itihue, en honor al rey Carlos IV (Manríquez, 2011). En 1822, el director supremo Bernardo O'Higgins dona la hacienda de Pemuco al general José Joaquín Prieto, por sus méritos durante la guerra de Independencia. Diez años más tarde contaba con trescientos habitantes, formando parte de un caserío en torno a la parroquia de la Inmaculada Concepción. En 1846 es nombrada aldea, para ser fundada formalmente, el 26 de noviembre de 1870, como villa de Pemuco.

Quillón, parte de la llamada Estancia del Rey, territorio reservado para la mantención de la guarnición militar permanente, tuvo ya en siglo XVII colonos españoles (Merino, 1986). En 1839 adquirió el nombramiento de villa de Quillón. La ciudad de Bulnes (Larqui) en 1788 
estaba conformada por un caserío en torno a la capilla de Larqui, en la ribera sur del río homónimo, hasta que en 1839 el presidente José Joaquín Prieto funda la ciudad de Bulnes, en honor al general Manuel Bulnes, vencedor en la batalla de Yungay en la Guerra contra la Confederación Perú-Boliviana. La ciudad de Yungay fue fundada el 20 de enero de 1842 por el general Fernando Baquedano, en honor del triunfo del ejército chileno conducido por Manuel Bulnes en la batalla de Yungay, el 20 de enero de 1839.

La villa de Portezuelo, según registros antiguos, constituyó una estancia llamada "Quilliquillay", perteneciente a Miguel de las Cuevas. Según el historiador Fernando Campos Harriet, su hija Margarita Cuevas Montecinos contrajo matrimonio con el capitán francés Rodrigo Martel de Durand, quién en 1776 la llamó "Portezuelo de Durand", disponiendo un palo de justicia para castigar a los infractores de la ley. Recibió al cacique Carrillanca y a su gente, formándose de a poco una aldea o pequeño villorrio en torno a las casas patronales. Su parroquia, Nuestra Señora del Carmen, data del año 1830. Dentro de sus límites se encuentra la exhacienda de Cucha-Cucha, propiedad de los jesuitas, distinguiéndose como la principal productora de vinos durante la época hispana.

Pinto fue fundada el 6 de octubre de 1860 por el intendente de Nuble José Manuel Pinto Arias, en homenaje a su padre Francisco Pinto Rebollar, héroe de la Patria Vieja en la Guerra de la Independencia. Sus orígenes se remontan a tiempos prehispánicos, siendo desde esa época zona de paso hacia la banda oriental de la Cordillera de los Andes. En la ruta también se encuentra la Cueva de los Pincheira, refugio de la banda de forajidos que aterrorizaron la zona hasta 1832, durante la llamada Guerra a Muerte. Es el camino a las Termas de Chillán, importante complejo turístico y espacio de gran significación cultural (Cartes y Reyes, 2016).

San Fabián, fundada el 7 de diciembre de 1865 por el agricultor propietario de esas tierras, Fabián de la Fuente, era escenario de las faenas de arrieros desde y hacia Argentina. Por esos años predomina la crianza de caprinos, ovinos y caballares. San Gregorio, fundada el 12 de septiembre de 1866, a instancias y donación del terreno por parte de Gregorio Caro, se caracteriza por la agricultura y ganadería. Formaron parte de esta tierra las ricas haciendas de Zemita y Vergüin, cuyo pro- 
pietario fue el político y minero Juan Francisco Rivas. San Ignacio fue creada en 1848 por los hermanos Faustino y Basilio Sandoval quienes donaron los terrenos, llamándola de esa manera en honor del primer intendente de Ñuble, Juan Ignacio García. El 19 de mayo de 1871 adquiere el título de villa.

Cobquecura (pan de piedra) recibió su título de villa en 1878, dependiendo de la provincia del Maule hasta 1927 (Zamora, 2013). Su existencia se remonta como poblado al siglo XVI. En su cercanía se encuentra el otrora puerto de Buchupureo (olas altas), que funcionó desde 1860 exportando cereales, vino y carbón vegetal por su muelle, hasta su desaparición en 1891.

El Carmen tiene su origen desde el año 1853, aunque existen antecedentes de que habría un pequeño caserío de gente avecindada en 1825. Su nombre tendría origen en la esposa de Candelario Cuevas, un antiguo propietario. En épocas pretéritas estuvo habitada por la etnia picunche, pueblo agricultor y sedentario que cultivaba el maíz. También en su territorio existió la hacienda Pal Pal, de propiedad del abuelo materno de O'Higgins, Simón Riquelme.

Coihueco (agua del coigüe) fue fundada como villa el 17 de julio de 1868 (Mora, 1996). Emplazado al oriente de la actual ciudad, existía un caserío llamado por los lugareños villa El Guindo, por la abundancia de ese frutal. Los terrenos para su fundación fueron donados por el agricultor Luis Hermosilla. Su principal actividad es forestal y agrícola, cuyos cultivos más relevantes son la remolacha, trigo y frutales. Alberga el Santuario de la Naturaleza y Reserva Nacional Los Huemules de Niblinto, y las Minas del Prado. Esta última, antigua mina de oro actualmente sin explotar.

Ninhue (lugar protegido de los vientos), cuyos orígenes se remontan al año 1688, por la existencia de la hacienda Coroney y la instalación de una capilla, denominada "San Antonio de Ninhue". El año 1770 los franciscanos construyeron un convento. Desde 1833 a 1891 dependió de la provincia del Maule. Aquí nació Arturo Prat Chacón, en la hacienda San Agustín de Puñual, el 3 de abril de 1848, siendo bautizado en la parroquia del pueblo el 2 de marzo de 1849.

Ránquil (agua de carrizal), en su territorio se registró el primer enfrentamiento entre españoles e indígenas, pasando a la historia como 
batalla de Reinogüelen, en 1536. En 1551 se introdujeron las primeras viñas y en 1701 se construye la primera capilla, bajo la advocación de Dulce Nombre de María. En la Independencia se lleva a cabo el combate de Quilo, el 19 de marzo de 1814. La comuna actualmente conserva el nombre de Ránquil, en recuerdo de su existencia, siendo su capital el pueblo de Ñipas, de mayor desarrollo. Inserto en el valle del Itata, su vocación ancestral es la producción de vinos.

San Nicolás. Sus orígenes se remontan al año 1686, con un pequeño poblado o pueblo de indios llamado "Quilling". Durante el siglo XIX estos terrenos pertenecían a Rosario Lantaño Vda. de Mieres, como parte del fundo Quillinco, y su fundación, en 1891, se realizó en un sitio que no figuraba con anterioridad ni como aldea, pueblo o caserío. Su nombre se supone ser en advocación a San Nicolás de Bari, al no tener tradiciones que justifiquen en la historia la decisión de darle ese nombre (Reyes, 2016). Su actividad productiva se basa en el cultivo de trigo, remolacha y frutas.

Trehuaco (agua del perro), poblamiento cuyo origen se encuentra en la segunda mitad del siglo XVIII en los fundos Quilpolemu y Minas de Leuque, además de los pueblos de indios de Mela y Maitenco, y la existencia de la hacienda jesuita de Torreón (Concha, 2010). Por esta tierra cruzaba el Camino Real que unía Quirihue con Concepción. A pesar de la fuerza de la producción forestal, aún se destaca por la producción de sus viñedos, papas, papayas y membrillos.

Durante la presidencia de Manuel Balmaceda se dictó una ley que permitió que varias de estas localidades fueron trasformadas en comunas. Entonces adquirieron esta categoría administrativa las de Chillán Viejo (hasta 1927), San Nicolás, San Gregorio, El Carmen, Coihueco, Pinto y San Ignacio. 


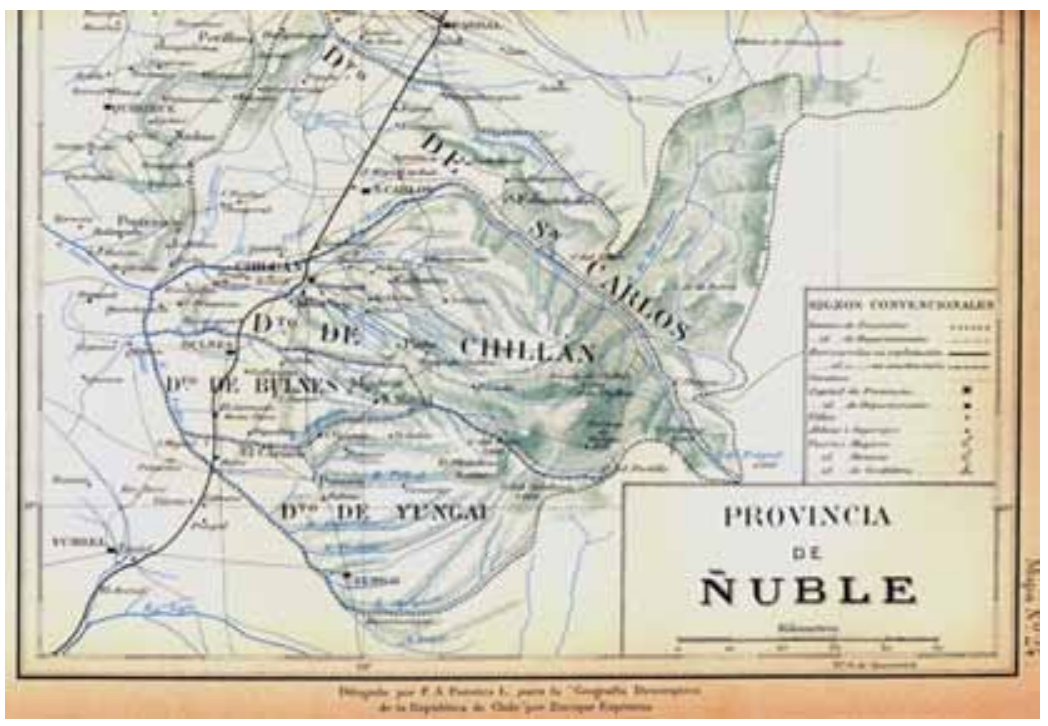

Figura $N^{\circ} 3$. Provincia de Nuble, 1903.

Fuente: Geografía descriptiva de la República de Chile, de Enrique Espinoza. Santiago, Imp. Lit. y Enc. Barcelona, 1903.

\section{El mercado de Chillán y la producción agropecuaria}

El mercado constituye un polo de atracción económica para la producción hortícola y agropecuaria. Su origen se remonta al siglo XVIII en lo que es hoy Chillán Viejo, y su influencia se extendía a una vasta zona que incluía el poniente argentino. En los primeros años de la década de 1790, el número de cabezas de ganado menor llegó a medio millón de ovejas y 150 mil carneros. Su foco era la producción y el comercio de trigo, cordobanes, sebo, grasa, cueros de vacunos y ovejunos, cecinas, carneros, lana, productos cárneos, charqui; todo para abastecer a Concepción, al comercio nacional y, a través del puerto de Talcahuano, al mercado peruano. Se vio incrementada su influencia por la celebración de parlamentos entre españoles y mapuche, generando una red de intereses mutuos en la que ambas partes se beneficiaban del intercambio de bienes, tales como metales, licores, ponchos y frazadas. El desarrollo económico de Chillán quedó íntimamente ligado a las actividades agropecuarias, características que mantiene hasta el día de hoy (Leaman de la Hoz, 1982: 29). Su importancia es reconocida no solo en plano económico, sino también cultural (Torres; Ruz y Arias, 2010). 
Durante el siglo XIX el mercado chillanejo fue la expresión de la vida fronteriza como una de las mayores plazas comerciales entre el Maule y la Frontera. A mediados de aquel siglo los mercados de California y Australia dieron gran impulso a la agricultura, especialmente en el cultivo del trigo. En 1850 la exportación de trigo se había elevado a 276.664 quintales y la de harina a 220.000 quintales. El mercado australiano recibió en 1855 la cantidad de 323.607 quintales de trigo. Al decaer estos mercados, en 1860 se abre el mercado europeo, lográndose exportar, solo a Inglaterra, 855.360 quintales de trigo.

La construcción del camino a Tomé facilitó el transporte del producto hacia ese puerto, tanto para el comercio nacional como internacional. En 1850 existían allí tres importantes molinos. Tres años después existían en la provincia de Ñuble un total de 115 molinos, y solo el departamento de Chillán contaba con 93. En 1863 la provincia era responsable del diez por ciento de la producción nacional. Aparte de la producción triguera, también el cultivo de cebada, maíz, frejoles, arvejas y papas alcanzó altos rendimientos. La producción vitivinícola en 1861, en el departamento de Chillán, llegó a 2.345.130 litros de vino; la producción de aguardiente, chacolí y chicha fue también cuantiosa. El número total de propiedades agrícolas en la provincia alcanzaba en 1855 a 3.174. Para 1874 no había variado mucho, siendo la cifra de 3.869, distribuida en 216 haciendas, 177 hijuelas y 3.476 fundos.

Desde el punto de vista urbano, el mercado era uno de los principales íconos de la ciudad. La feria chillaneja, que se realizaba todos los días sábado, recibía ganaderos de los departamentos ubicados al sur del río Maule y de la frontera araucana (Leaman de la Hoz, 1982: 30). El 30 de septiembre de 1852 el municipio acordó trasladar la recova a dos sitios que poseía en el costado norte de la plaza de La Merced. Esta plaza quedó exenta de árboles, para que allí se ubicaran cientos de carretas, instalándose en ella la feria.

\section{Un desarrollo industrial frustrado}

A partir de mediados del siglo XIX la actividad agropecuaria incentivó la creación de establecimientos industriales que cubrían las necesidades en el rubro. Se establecieron maestranzas agrícolas, tonelerías, curtiembres, fábricas de zapatos, cervecerías, locales de elaboración 
de maderas, herrerías mecánicas y fábricas de carruajes. El primer impulsor de la industria chillaneja fue el norteamericano Guillermo Davison, quien creó la primera maestranza, para la fabricación de toda clase de herramientas agrícolas, con hornos de fundición, secciones de herrería y carpintería, de mecánica y fábrica de carruajes. En 1873 contaba con 50 operarios. Comercializaba por representación trilladoras, segadoras y cortadoras de pasto indispensables para la agricultura. Sus trabajos en madera aportaron fabricación de muebles y artículos de tonelería. Poseía, además, un molino en la ciudad.

En 1865 existían tres curtiembres en la ciudad, posibilitando el surgimiento de fábricas de zapatos, llegando una de ellas, a fines de siglo, a confeccionar doscientos pares al día, comercializando el producto al resto del país. Funcionaba anexo una fábrica de cajas de cartón para embalar el calzado, trabajo ejecutado por 40 niños de la Casa de Huérfanos. En 1869 los establecimientos industriales consistían en fábricas cerrajeras, herrerías mecánicas, hojalaterías y fábricas de carruajes (Leaman de la Hoz, 1982: 34-39).

El ramo de la cervecería tuvo un fuerte impulso a partir de 1868, con la creación de la Viña Schleyer, con cervecería anexa. El surgimiento de nuevas fábricas llevó la producción total a 490 mil litros de cerveza, en 1875, la que se destinaba al mercado local y provincial. Múltiples aserraderos y barracas en la ciudad daban cuenta de la producción en las zonas de Yungay, Pemuco, Coihueco, Cato y Boyén, que luego se destinaba al mercado de Talca y Santiago. Otros establecimientos de importancia fueron las fábricas de tejas y ladrillos: nueve a fines de siglo. Fábricas de fideos, conservas de frutas y legumbres, limonada y bebidas gaseosas, completaban la oferta industrial de la ciudad. Así fue en el siglo XIX, en particular en torno a las actividades y las maestranzas agrícolas. En este proceso, entre 1880 y 1920 las colonias extranjeras hicieron una fuerte contribución a la vocación comercial de Chillán (Reyes, 2010: 65).

Al desarrollo comercial e industrial debe sumarse el financiero. El primer banco de Chillán fue el Banco Montenegro y Cía., establecido en 1869 por iniciativa de Juan Ignacio Montenegro, también su gerente y que tuvo como socio en comandita a Mariano Ignacio Prado, general peruano y presidente del Perú (1865-1868, 1876-1879), quién residía en Santiago. Estimuló el desarrollo del comercio y de la agricultura 
hasta cerrar sus puertas, en 1874. Una segunda iniciativa de vecinos de Chillán y Concepción fue la constitución de la sociedad anónima Banco del Sur, que operó desde mayo de 1870. Sus gerentes fueron Salustio Casanueva y, en Concepción, Carlos Castellón. Liquidó sus capitales en 1871.

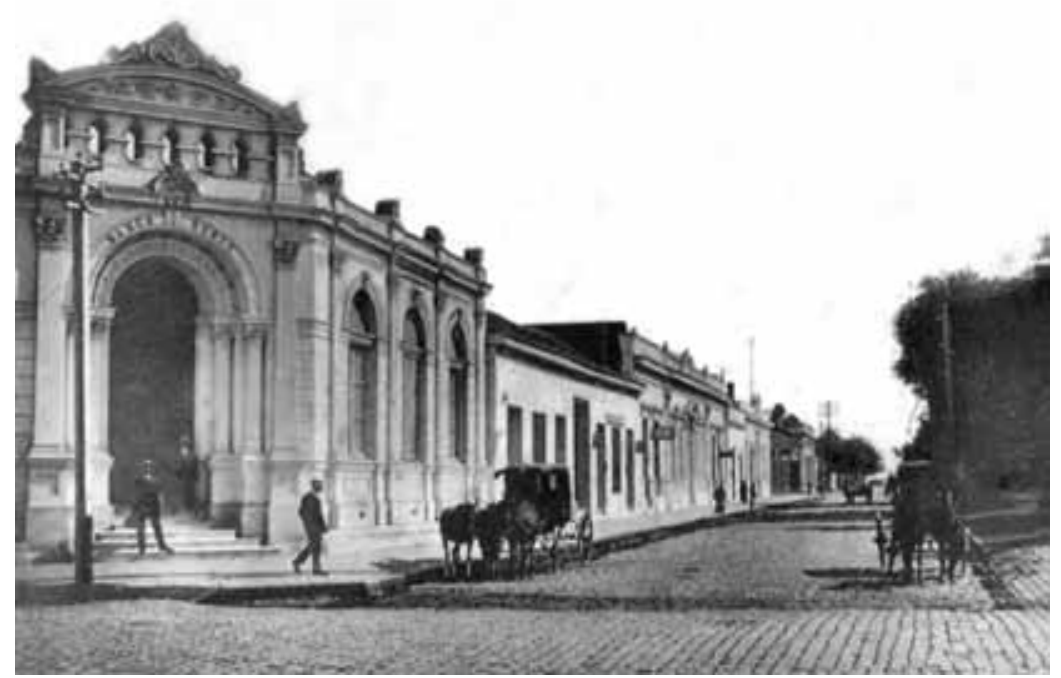

Figura $N^{\circ} 4$. Banco de Nuble.

Fuente: Calle Constitución, Chillán, Postal, c.1915.

El Banco Nacional de Chile abrió la primera sucursal bancaria creada en Chillán, iniciando actividades el 1 de marzo de 1870; la siguieron diversos bancos del país, entre ellos el Banco de Concepción, instalándose en marzo de 1873 con una sucursal dirigida por Ruperto Martínez. La sociedad anónima Banco de Ñuble, en tanto, abrió sus puertas el 26 de febrero de 1887, con un capital de 500 mil pesos; era manejado por un Consejo Administrativo compuesto por cinco miembros propietarios, nombrados por la Junta General de Accionistas. La institución favoreció la agricultura, el comercio y la industria en la zona, operando por más de 30 años. Emitió billetes con los mismos privilegios que los de la Caja de Crédito Hipotecaria. De esta forma, hacia 1893, la ciudad contaba con tres bancos: el Banco de Nuble, el de Chile y el Banco de Santiago (Márquez, 2015: 117-122). 


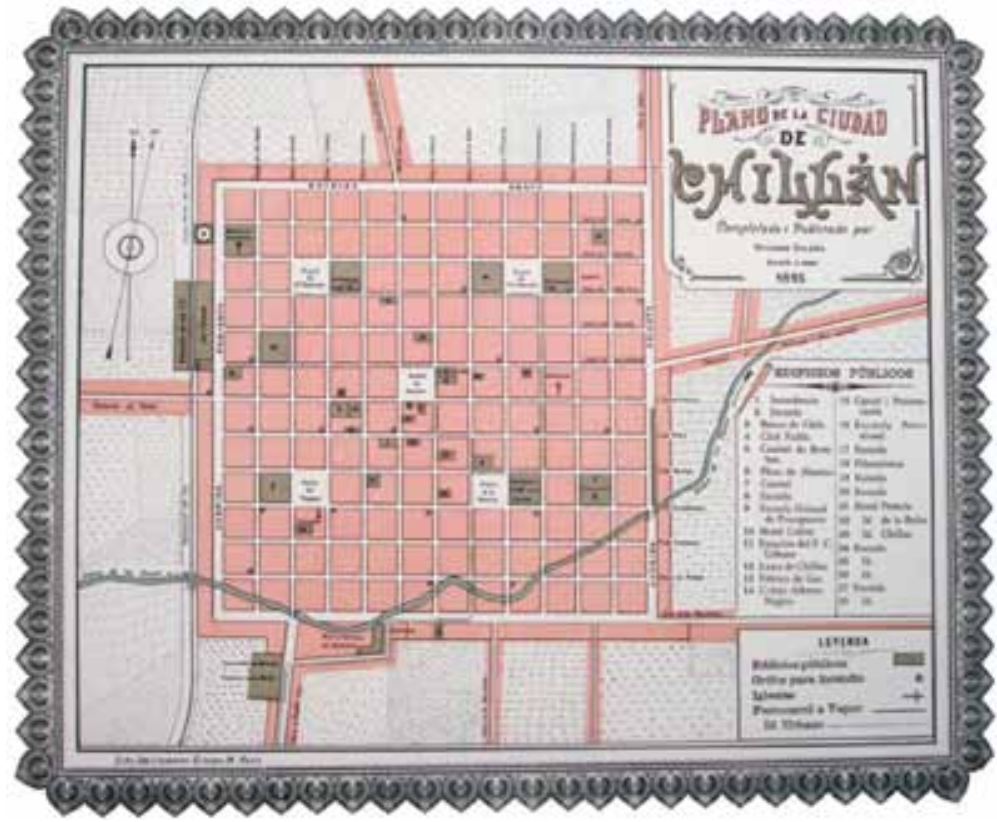

Figura N55. Chillán en 1895.

Fuente: Álbum de planos de las principales ciudades y puertos de Chile, por Nicanor Boloña. Santiago, Dirección General de Obras Públicas, Sección de Geografía y Minas, 1896.

A pesar de estos tempranos desarrollos, el siglo XX vio una estagnación. “¿Por qué Chillán dejó de ser ciudad industrial?”, se pregunta Reyes Coca. Patricio Parra señala que "la causa está en la fuerte ligazón de la industria local a la actividad agropecuaria, a las opciones de la oligarquía por invertir en inmuebles rurales y en el comercio, y por sobre todo, en la escasa conciencia empresarial que impidió la conformación de sociedades anónimas, esenciales para el desarrollo industrial." (Reyes, 2011). Añadamos que, en el siglo pasado, la política cepalina de industrialización forzada castigó, en los hechos, a las regiones agrícolas. Favoreció, en cambio, a las grandes metrópolis, con abundante mano de obra y acceso a puertos. Sin duda el tema merece una reflexión mayor.

\section{Chillán en el siglo XX}

Hacia 1930 la ciudad mantenía su tradicional estructura. Su población ascendía a 39.511 habitantes. Habían surgido varios barrios y pobla- 
ciones, como Villa Alegre, Zañartu, Chillancito o Santa Elvira. El resto de la periferia urbana estaba conformada por pequeñas y medianas propiedades agrícolas dedicadas a la horticultura y chacarería, y destinadas al abastecimiento de la ciudad. (Reyes, 1999: 66). La generalidad de las construcciones era de adobe o de ladrillo. El comercio continuaba siendo muy activo. Rodeado de una zona agrícola de intensa actividad, dio origen al mercado o feria libre, que permitía el trato directo del productor al consumidor. La ciudad mostraba una progresista actividad industrial, impulsada por integrantes de las colonias francesa, vasco-francesa, italiana, alemana y española. Árabes y españoles destacaban en el comercio.

La sociabilidad de la élite se manifestaba en el Club de Ñuble, fundado en junio de 1878, que tuvo gran influencia patrocinando obras de adelanto y acuerdos comerciales para el desarrollo de la zona. Hacia 1857 los inmigrantes alemanes crearon el Club Alemán de Chillán; en 1897 los españoles la Sociedad Española de Beneficencia, antecesora del actual Centro Español, y a principios del siglo XX los principales comerciantes el Club Comercial, a fin de socializar y tener un punto de encuentro para sus negocios y la defensa del gremio. La colonia italiana formó una entidad llamada Sociedad de Socorros Mutuos, presidida en 1898 por Vicente Bono.

La Sociedad de Artesanos La Unión fue creada el 29 de agosto de 1869, teniendo como objetivo la fraternidad y socorro mutuo de los obreros, promocionando su instrucción, la moralidad y el bienestar. Mantuvo una escuela nocturna para adultos y una diurna para niñas. Las sociedades obreras fueron importantes para obtener conquistas sociales y resolver problemas colectivos en los años en que el Estado se hallaba todavía ausente. La modernización económica, impulsada por las elites locales y los representantes del Estado, provocó tensiones. Ambos sectores promovieron al control social de la población, según Marco Antonio León, "para formar un ser moral, es decir, un ciudadano obediente, trabajador y sometido por la autoridad" (2015: 8).

Un extraordinario avance fue la creación de la Escuela Normal de Preceptoras, fundada por decreto del 9 de marzo de 1871 durante el gobierno de José Joaquín Prieto. Su primera directora fue la educadora Mercedes Cervelló. En 1873 tenía 41 jóvenes internas, de las cuales 25 eran becadas por el gobierno. Con fecha de 24 de febrero de 1888 
se decretó la creación de la Escuela Normal de Preceptores, iniciando sus actividades el 17 de abril del mismo año, con una matrícula de 40 alumnos; cifra que en 1894 había llegado a los 137 futuros educadores. En el año 1894 asumió la dirección Juan Madrid, destacado maestro con perfeccionamientos en Europa. Se desempeñó en tal cargo hasta el año 1921, logrando elevar la escuela entre las mejores del país. La Escuela Normal llevó su nombre en años posteriores hasta su cierre.

Otro importante establecimiento de educación profesional fue la Escuela Práctica de Agricultura, creada en el gobierno de Domingo Santa María, el 25 de agosto de 1885. Sus primeros profesores fueron contratados en Europa, siendo su primer director Rodolfo Meyer von Schanensen. En 1894 la matrícula alcanzaba a 20 alumnos, llegando a 50 en 1896. El predio que ocupaba, donde hoy se sitúa la Universidad de Concepción, se transformó en Quinta Agrícola, paseo preferido de los vecinos chillanejos. Su aporte radica en haber proporcionado mano de obra especializada a la agricultura, influyendo en el desarrollo de esta actividad en la provincia.

Diversas obras de progreso se fueron inaugurando con los años. El Servicio de Correos operaba desde 1855, a lomo de mulas, comunicando pueblos y ciudades. Chillán quedó integrada a la línea telegráfica en 1866, apresurada por el conflicto con España. En el mes de noviembre de 1888 la municipalidad autorizó tender líneas telefónicas en la ciudad a la empresa West Coast Telephone Company. Los primeros teléfonos fueron instalados, entre otras instituciones, en la intendencia, la municipalidad, la estación de ferrocarriles, el hospital, Registro Civil, el Club de Ñuble, las compañías de gas y agua potable, los juzgados, etc. En 1892 se produce conexión con Concepción y en 1897 con Talca.

Un importante impulso al desarrollo industrial lo constituyó la llegada del ferrocarril. En 1872 se llamó a propuesta pública para la construcción de la vía entre Chillán y Concepción-Talcahuano. Su inauguración, que traía la conectividad y el progreso para aquella ciudad y la zona aledaña, se celebró el 15 de abril de 1874. El demorado Ferrocarril del Sur, en tanto, en el tramo de la sección central desde Curicó a Linares y Chillán, se inauguró más tarde.

La Corte de Apelaciones de Chillán fue creada el 8 de agosto de 1936, por ley 5.867. Se plasmó su instalación el 13 de enero de 1937, 
presidida por el ministro Rafael Fontecilla Riquelme. El consejo local del Colegio de Abogados se creó de inmediato, el 19 de mayo de 1937, siendo su primer presidente Alfonso Quintana Burgos.

La Diócesis San Bartolomé de Chillán fue creada por el Papa Pío XI el 18 de octubre de 1925, mediante la Bula Notabiliter Aucto. Se separó de la diócesis penquista la parte que comprendía la provincia de Ñuble y los departamentos de Cauquenes, Chanco e Itata de la provincia de Maule, con veintidós parroquias. Con estos se erigió la Diócesis de Chillán, llamada así por la ciudad de Chillán, la sede episcopal, y su Iglesia parroquial de San Bartolomé Apóstol recibió la dignidad de Iglesia Catedral. Martín Rücker Sotomayor fue su primer Obispo (León, 2018). ${ }^{3}$

\section{El terremoto de 1939 y el Chillán moderno}

En la noche del 24 de enero de 1939, pasadas las 11:30 horas, se registró un violento terremoto que destruyó prácticamente toda la ciudad, dejando miles de muertos y sembrando el pánico en la población. Su epicentro tuvo lugar en Quirihue, expandiendo sus ondas en parte del territorio desde Valparaíso a Temuco y, en el extranjero, hasta Mendoza y Buenos Aires. Se trató de una serie de movimientos ondulatorios que sacudieron la tierra por varios minutos, seguidos de réplicas posteriores, lo que explica el enorme daño en las construcciones antiguas de Chillán.

El aspecto que ofrecía la ciudad era desolador, calles cubiertas con escombros, postes de luz y árboles en el suelo, algunos incendios declarados, heridos y personas despavoridas buscando sus seres queridos. Se estima en 15 mil las víctimas en Chillán y 40 mil en la región. No se conoce con exactitud el número de víctimas fatales, por haber sido sepultadas con premura y sin la inscripción de la defunción para impedir brotes epidémicos. Sus cuerpos fueron depositados en una fosa común en el cementerio de la ciudad. Muchas familias desaparecieron completamente (Reyes, 1989: 62-70).

3 Sucedieron a Rücker, Jorge Larraín Cotapos (1937-1955); Eladio Vicuña Aránguiz (1955-1974); Francisco José Cox Huneeus (1975-1981); José Alberto Jara Franzoy (19822006); Carlos Eduardo Pellegrin Barrera (2006-2018) y Sergio Pérez de Arce Arriagada, desde julio de 2020. 
La ciudad experimentó un intenso crecimiento horizontal, derivado de las disposiciones que impedían la edificación en gran altura. Se impulsó la construcción de nuevas poblaciones sin considerar las características del terreno, sumando la fragilidad del hábitat a la expansión urbana. El plano regulador urbano de 1963 vino a ordenar la ciudad que crecía agigantándose, tanto en espacio como en población, pasando de 42.817 habitantes en 1940, a 59.654 que se contabilizaron en el censo de 1960.

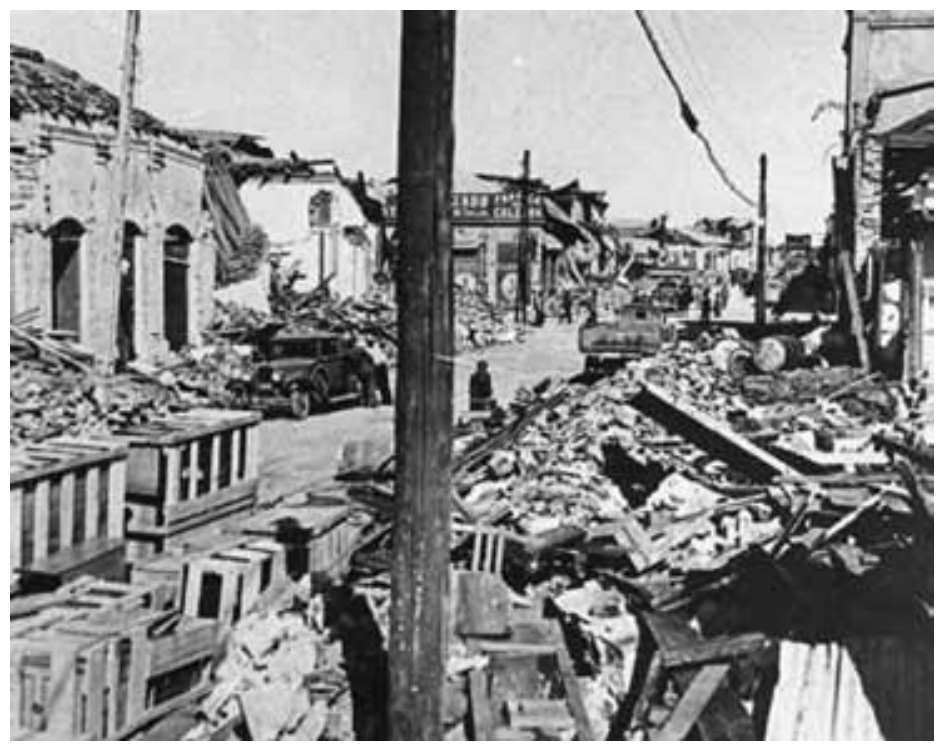

Figura $N^{\circ} 6$. Terremoto de 1939.

Fuente: Fotógrafo desconocido, Archivo personal del autor.

Desde entonces la ciudad capital no ha dejado de crecer. Se van incorporando los terrenos y sitios que separaban los dos emplazamientos de Chillán, fundiéndose tanto el nuevo Chillán con Chillán Viejo, conformando una intercomuna conurbada. El centro concentra edificios en altura, servicios financieros y comerciales, así como el centro cívico destinado a las actividades públicas, de comercio y sociales de la ciudad. En la salida norte de Chillán y sur de Chillán Viejo, como el camino al sector del Huape, diversos loteos industriales han permitido que allí se instalen industrias y diversas empresas de mayor magnitud. Hacia la salida del camino a Coihueco y a Cato se van desarrollando loteos residenciales, produciéndose un éxodo de vecinos hacia estas 
nuevas locaciones y otras zonas habitacionales. La expansión urbana constante plantea el desafío de la densificación y la conectividad (Basterrica, 2015: 80).

\section{Nace la Región de Ñuble}

La creación de la actual Región era una antigua aspiración de muchos vecinos. La estimulaba el recuerdo de la provincia decimonónica, la fuerte identidad histórica del territorio, así como la frustración que provocaba el centralismo del país y el intrarregional que atribuían a la ciudad capital del Biobío, Concepción. Se concretó con la creación del Comité Ñuble Región, en 1997, constituido por más de 40 instituciones sociales y culturales. El proyecto va concitando un creciente apoyo de los alcaldes, parlamentarios, consejeros regionales y de la sociedad civil. Pasaron a integrarlo los alcaldes de las 21 comunas de la provincia. ${ }^{4}$ Por años realizaron múltiples acciones, a nivel político, académico y comunicacional, para promover la iniciativa. Se disolvió en 2018, por cumplimiento de sus objetivos. ${ }^{5}$

En 2013 el gobierno licitó un estudio de factibilidad, adjudicándose dicha investigación la Universidad de Concepción (Chile, 2013). Las aspiraciones apuntaban a que la nueva región sería de vocación agroalimentaria, turística, deportiva, artística, comercial, con potencial en la pesca, la minería y un importante puerto seco para el sur del país. Diversos estudios buscaron caracterizar al territorio y establecer la factibilidad del proyecto regional en sus dimensiones geográfica, humana, económica y cultural (Umaña, 2015). Los datos mostraban que Nuble era una provincia altamente ruralizada (35\%). Tenía 21 comunas y era la provincia con la mayor cantidad de municipios del país. Se detectaron importantes potencialidades y vocaciones no aprovechadas, más otras actividaddes que requieren una mayor sustentabilidad. Hay grandes estructuras poco intensivas en empleo (Catalán, 2020). Aunque posee industria y potencial urbano, la agricultura es la acti-

4 Ver la publicación conmemorativa de la creación de la Región, La Historia de Ñuble Región (Chillán, 2018).

5 Los documentos históricos, libros de registros, actas y archivos de cartas del Comité Nuble Región fueron entregados al Museo Antropológico de Quirihue el 27 de mayo de 2018, dando término a su gestión por el cumplimiento de sus objetivos. 
vidad más importante, lo que marca la construcción identitaria de su población.

El proyecto comienza a tomar forma en 2013, con su inclusión en el programa presidencial de Michelle Bachelet. Fue el jueves 23 de mayo de ese año, recuerda el senador Felipe Harboe, cuando la futura presidenta "llegaba como candidata en las primarias y en un caótico encuentro frente al mercado (de Chillán), comprometió su apoyo a la creación de la región de Nuble (...) compromiso que ratificó ya como candidata de la coalición el sábado 2 de noviembre en un masivo acto frente a la Gobernación". 6 El 20 de agosto de 2015 la presidenta de la República firmó el proyecto de ley en un acto en presencia de alcaldes y fuerzas vivas de la comunidad de Ñuble.

El 20 de diciembre de 2016 se aprobó el proyecto de ley Ñuble Región en la Comisión de Hacienda, despachándolo a sala del Senado para ser votado definitivamente el 10 de enero de 2017. Ese día se aprueba el proyecto de creación de la XVI Región de Ñuble en el Senado. Después de intensas negociaciones legislativas, el proyecto de ley que segregaba la Provincia de Ñuble fue promulgado en Chillán el 19 de agosto de 2017. La nueva región contaría con tres provincias: Diguillín, Itata y Punilla. El 5 de septiembre de 2017 se publicó la ley 21.033 que crea la XVI Región de Ñuble (Harboe, 2018). Así se concretaba un antiguo anhelo; vendrán mejores tiempos para un antiguo territorio, devenido en flamante Región, la que está vigente desde el 6 de septiembre de 2018.

La actual Región, con una superficie total de 13.178,5 kilómetros cuadrados, es la más pequeña de Chile, incluso que la Metropolitana. Según el censo de 2017, tiene una población de 480.609 habitantes, de la cual un $69,4 \%$ corresponde a población urbana y el resto a población rural. La conforman tres provincias y 21 comunas, su capital es la ciudad de Chillán. Limita al norte con la Región del Maule, al este con la provincia de Neuquén, en Argentina, al sur con la Región del Biobío y al oeste con el Océano Pacífico.

6 "Así presentó el senador Harboe su libro Región de Ñuble, del sueño a la realidad": https://www.harboe.cl/post/2018/08/30/asi-presento-el-senador-harboe-su-libroregion-de-nuble-del-sueño-a-la-realidad 


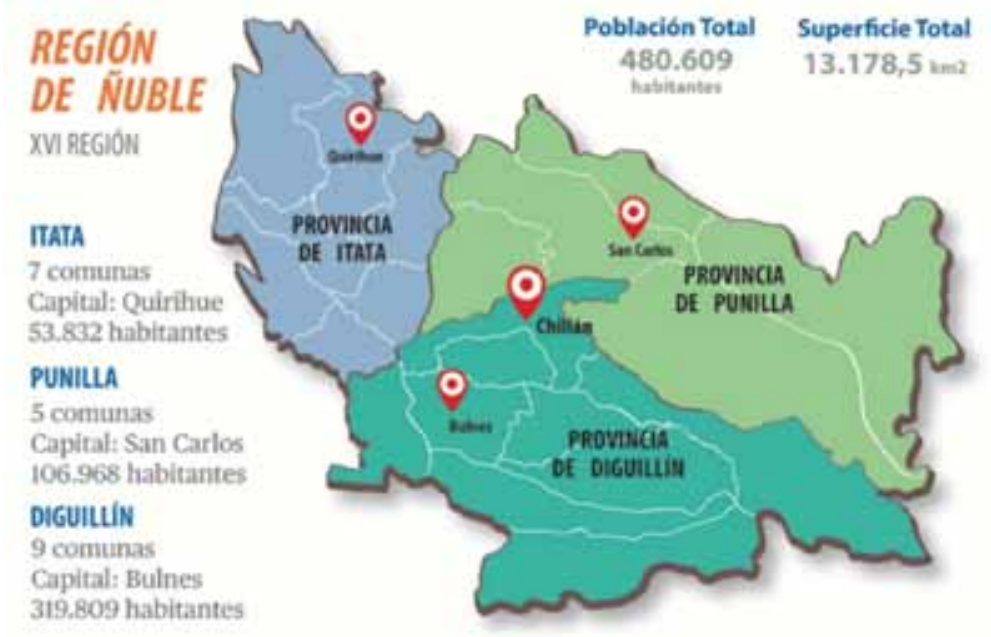

Figura $N^{\circ} 7$. Región del Ñuble, 2018.

Fuente: Departamento de Educación, DAEM, Portezuelo. En https://www.daemportezuelo.cl.ubicacion.php

Sus principales centros urbanos son Chillán y San Carlos. Las siguientes ciudades con mayor población, todas ubicadas en la depresión intermedia, son San Carlos, Coihueco, Bulnes y Yungay; a las que se agrega Coelemu, situada en la cordillera de la Costa, en las cercanías del río Itata. Las ciudades más pobladas de la Región, según el Censo de 2017, son la conurbación Chillán-Chillán Viejo, con una población de 215.646 habitantes, y San Carlos, con 53.024.

Aunque su costa es reducida, la menor del país, es la única provincia del Biobío que iba de mar a cordillera. Se ubica en la zona de transición de Chile Centro-Sur. Los sistemas montañosos son dominantes. Hay gran dominancia de Chillán, por su peso demográfico comparativo, en su área de influencia de nodos y centros poblados. Exhibe preocupantes cifras de pobreza rural, alta migración campo-ciudad, deficientes técnicas de trabajo de la tierra y uso del suelo, proliferación de la pequeña propiedad y agricultura de subsistencia (Rebolledo, 2015). Las tasas de pobreza e indigencia son superiores al resto del país y el promedio regional; es Ñuble la provincia con menor crecimiento poblacional (Fawaz, 2015), aun cuando está experimentando una renovación importante derivada del proceso de modernización. 


\section{Conclusión}

La creación de la Región de Ñuble, en 2018, dio cumplimiento a una antigua aspiración de reconocimiento y desarrollo de la provincia homónima. La demanda de regionalidad se afincaba en la fuerte identidad del territorio, asociada a su vocación agrícola y su pasado histórico; pero también a las frustraciones que provocaba el doble centralismo, regional e intrarregional, que la provincia venía denunciando. Los estudios que acompañaron a su gestación y la instalación de la Región, en efecto, evidenciaron su rezago social y productivo.

He pasado revista a diversas dimensiones de su devenir histórico, en lo urbano, económico, social y cultural, siempre afincado a un territorio que, en buena medida, ha marcado su desarrollo. Los ríos Nuble e Itata, en efecto, han sido límites, pero sobre todo el nutriente necesario para la agricultura y la población. La vocación agrícola, hoy matizada con la actividad forestal, es otro elemento distintivo. La cordillera cercana, que acoge parajes tan importantes como los baños termales de Chillán, ha sido, a la vez, factor de identidad y fuente de actividad económica.

El breve tiempo transcurrido desde su creación no permite todavía ponderar, de manera significativa, el desempeño de la Región de Ñuble. Ha habido problemas con su instalación, propios de la inexperiencia y de la necesidad de recrear prácticas políticas, programas y capacidades forjadas en el casi medio siglo de la Región del Biobío.

Su fuerza política se manifestará en una alta representación parlamentaria - en relación a su población-y la inminente presencia de autoridades regionales elegidas. En 2021, en efecto, debería concretarse la elección de gobernadores regionales, lo que dotaría de legitimidad, estabilidad y mayor capacidad de negociación al ejecutivo regional. Desde 2009 los consejos regionales son de generación plenamente democrática.

Se ha observado, en lo cultural, un reforzamiento del rescate y promoción de la identidad local y regional, a través de publicaciones y decenas de organizaciones de índole literario, histórico y artístico que corresponden a una tradición de Ñuble, pero que ahora se han visto 
fortalecidas ${ }^{7}$. La creación del feriado local del 20 de agosto, para Chillán y Chillán Viejo, a partir de 2014, por el natalicio del Libertador, ilustra la especial aproximación regional a procesos históricos nacionales. ${ }^{8}$

En el ámbito público, asistimos a una visibilización de problemas y diagnósticos que son previos y resultan indispensables para acometer las mejoras necesarias. La inversión pública tenderá a compensar los rezagos señalados en los indicadores sociales, a la vez que a potenciar la vocación agroindustrial de la región, mediante inversiones específicas en riego, conectividad y fomento productivo.

El desafío que enfrenta Ñuble consiste en traducir en un progreso efectivo la mejorada gestión política y técnica que ofrece la condición regional para cada una de las 21 comunas que la componen. Es la gran tarea de los próximos años.

\section{Referencias bibliográficas}

Fuentes primarias

\section{a) Publicaciones oficiales}

Comisión Nacional de la Reforma Administrativa (1976). Chile hacia un nuevo destino. Su reforma administrativa integral y el proceso de regionalización. Santiago: Ed. Gabriela Mistral.

Chile (1889). Sesiones de los Cuerpos Lejislativos, tomo XII. Santiago: Imprenta Cervantes.

Chile (1927). Decretos con Fuerza de Ley 8.582 y 8.583, del 30 de diciembre.

$7 \quad$ Es muy destacable la acción de intelectuales y gestores culturales, como Carlos René Ibacache o Alejandro Witker, creadores de las revistas Cauce y Quinchamalí, publicaciones señeras en la difusión de la actividad literaria y el patrimonio histórico cultural. Instituciones como la Escuela de Cultura Artística Claudio Arrau León, de Chillán, hacen una contribución. Una pléyade de escritores, repartidos por todas las comunas, aportan a la creación literaria. Algo similar puede decirse en diversos campos. Ver Arriagada (2015: 157-175).

8 Ley 20.768, promulgada 18 de agosto de 2014. El 19 de agosto de 1966, bajo la presidencia de Eduardo Frei Montalva, fue promulgada la Ley 16.535, la cual declaró feriado escolar en la comuna de Chillán el 20 de agosto, con motivo de la "fecha del nacimiento del prócer de la Independencia, general don Bernardo O'Higgins”. 
Chile (2013). Informe final, Linea base, Consideraciones y propuestas técnicas para determinar pertinencia de creación de Nueva Región de Nuble. Concepción: Universidad de Concepción.

Oficina de Informaciones y Difusión de la Presidencia de República (1966). Dos años de Gobierno en la Región del Bío-Bío, 3 de noviembre de 1964, 3 de noviembre de 1966. Concepción: Escuela Tipográfica Salesiana.

b) Publicaciones periódicas

La Historia de Ñuble Región, Chillán, 2018.

Fuentes secundarias

a) Artículos y capítulos de libros

Arriagada, F. (2015). "Escritores del Itata", en A. Cartes (Editor), Chillán, las Artes y los Días, Concepción: Ediciones del Archivo Histórico de Concepción, pp. 157-175.

Basterrica, J. (2015). "El desarrollo urbano de Chillán desde 1835", en A. Cartes (Editor), Chillán, las Artes y los Días, Concepción: Ediciones del Archivo Histórico de Concepción, pp. 45-81.

Estefane, A. (2017). "Estado y ordenamiento territorial en Chile", en I. Jaksic y J. L. Ossa (Editores), Historia política de Chile. Tomo II: Estado y Sociedad. Santiago: Fondo de Cultura Económica, Universidad Adolfo Ibáñez, pp. 87-138.

Fawaz, M. (2015). “Una mirada analítica de la provincia de Ñuble desde el sector rural, la mujer y la familia", en B. Umaña (Editor), Caracterización de la Provincia de Nuble, y una propuesta estratégica para el desarrollo del territorio. Concepción: Ediciones Universidad del Biobío, pp. 181-276.

Márquez, B. (2015). “Actividades comerciales e industriales del antiguo Chillán: 1835-1939", en A. Cartes (Editor), Chillán, las Artes y los Días. Concepción: Ediciones del Archivo Histórico de Concepción, pp. 105-122.

Rebolledo, J. (2015). "Bases físico-ambientales para el desarrollo sustentable de la provincia de Ñuble", en B. Umaña (Editor), Caracterización de la Provincia de Nuble, y una propuesta estratégica para el desarrollo del territorio. Concepción: Ediciones Universidad del Biobío, pp. 15-132.

Restall, M. (2000). "Black Conquistadors: Armed Africans in Early Spanish America", en The Americas, vol. 57, N², pp. 171-205. 
Reyes, M. (2010). “Colonias extranjeras en Chillán”, en Quinchamalí, N¹. Sanhueza, M. (2008). "La primera división político-administrativa de Chile”, 1811-1826, en Historia, vol. II, N41, julio-diciembre, pp. 447-493.

\section{b) Libros}

Cartes, A. (Editor) (2015). Chillán, las Artes y los Días. Concepción: Ediciones del Archivo Histórico de Concepción.

Cartes, M. y F. Arriagada (2008). Viñas del Itata. Una historia de cinco siglos. Concepción: Editorial Pencopolitana.

Cartes, M. y M. Reyes (2016). Los Baños minerales de Chillán, una comarca en la cordillera. Concepción: Ediciones Universidad del Biobío.

Carvajal, K. (s/a). Juan Valiente, de esclavo a Capitán con Pedro de Valdivia. Santiago: Liberalia.

Concha, S. (2010). Trehuaco y su historia, Santiago: René Darrouy Impresor.

Gomáriz E. (2016). El Osado Negro Juan Valiente. Silex.

Gómez, F. (1889). Historia geográfica, natural y civil del Reino de Chile. Tomo I. Santiago: Imprenta Ercilla.

Harboe, F. (2018). Región de Nuble, del sueño a la realidad, cronología legislativa. Santiago: Editorial Catalonia Ltda.

Leaman de la Hoz, F. (1982). Historia urbana de Chillán 1835-1900. Chillán: Instituto Profesional de Chillán.

León, M. (2015). Cultivando un ser moral. Orden, progreso y control social en la provincia de Ñuble (1848-1900). Chillán: Ediciones Universidad del Biobío.

León, M. (2018). Martín Rücker Sotomayor, una vida sin "descanso en el trabajo" (1867-1935). Santiago: Sociedad de Historia de la Iglesia en Chile - Centro de Estudios Bicentenario.

Manríquez, V. (2011). Reminiscencias Sancarlinas. Historia e imágenes de San Carlos. Chillán: La Discusión.

Martínez, F. (1980). Reseña histórica de Chillán. Chillán: Universidad de Chile.

Medina, J. (1952). Los aborígenes de Chile. Santiago: Fondo Histórico y Bibliográfico José Toribio Medina.

Merino, P. (1986). Quillón, Atisbos de mi tierra. Chillán: Impresos Duch. 
Mora, Z. (1996). Coihueco: dos raíces de una cultura (1552-1996). Temuco: Editorial Kushe.

Muñoz, R. (1921). Chillán, sus fundaciones y reconstrucciones, Santiago: Imprenta de San José.

Pedrero, P. (2008). Chillán Viejo, llave del reino y cuna de la patria. Concepción: Editorial Pencopolitana Ltda.

Pedrero, P. (2017). Cucha-Cucha, Patrimonio histórico-productivo del valle del Itata. Chillán: Impresos La Discusión.

Reyes, M. (1989). Iconografía de Chillán 1835-1939. Chillán: Ediciones Universidad del Biobío.

Reyes, M. (1999). Breve Historia de Chillán 1835-1939. Concepción: Cuadernos del Biobío.

Reyes, M. (2011). Crónicas Chillanejas. Concepción: Cuadernos del Biobío.

Reyes, M. (2016). Historia de la comuna de San Nicolás. En busca de nuestra identidad comunal. Chillán: Municipalidad de San Nicolás-Universidad del Biobío.

Roa, L. (1945). El Reyno de Chile. 1535-1810. Estudio Histórico, Genealógico y Biográfico. Valladolid: Instituto “Jerónimo Zurita”.

Rosales, R. (1877) Historia General del reino de Chile. Flandes Indiano. Valparaíso: Imprenta de El Mercurio.

Sagredo, R., J. I. González y J. Compan (2016). La política en el espacio. Atlas Histórico de las divisiones político-administrativas de Chile, 1810-1940. Santiago: Centro de Investigaciones Diego Barros Arana, PUC, Instituto Geográfico Militar.

Sala, J. (1986). Visita general de la Concepción y su obispado por Fray Pedro Ángel de Espiñera. Su meritísimo prelado (1765-1769). Chillán: Ediciones Instituto Profesional de Chillán.

Torres, F., P. Ruz y L. Arias (2010). Mercado de Chillán. Iconografía de una Historia. Talcahuano: Trama Impresores S.A.

Umaña, B. (Editor) (2015). Caracterización de la Provincia de Nuble y una propuesta estratégica para el desarrollo del territorio. Concepción: Ediciones Universidad del Bio-Bio.

Villalobos, S. (1995). Vida fronteriza en la Araucanía, Santiago: Editorial Andrés Bello.

Zamora, L. (2013). Cobquecura, Pan de Piedra, Piedra de Lobos. Quirihue: Impreso Artesanal Lamur. 


\section{c) Otros}

"Así presentó el senador Harboe su libro Región de Ñuble, del sueño a la realidad", en

https://www.harboe.cl/post/2018/08/30/asi-presento-elsenador-harboe-su-libro-region-de-nuble-del-sueño-a-larealidad, revisado el 20 de junio de 2020.

d) Tesis

Catalán, G. (2020). Extractivismo forestal y rezago socioeconómico estructural: el caso de la provincia del Itata. Tesis para optar al grado de Magíster en Política y Gobierno de la Universidad de Concepción. Concepción, Chile: Universidad de Concepción. 